\title{
WNT signaling suppresses oligodendrogenesis via Ngn2-dependent direct inhibition of Olig2 expression
}

\author{
Min Jiang, Dan Yu, Binghua Xie, Hao Huang, Wenwen Lu, Mengsheng Qiu* and Zhong-Min Dai* (1)
}

\begin{abstract}
Olig2 transcription factor is essential for the maintenance of neural progenitor cells (NPCs) in the pMN domain and their sequential specification into motor neurons (MNs) and oligodendrocyte precursor cells (OPCs). The expression of Olig2 rapidly declines in newly generated MNs. However, Olig2 expression persists in later-born OPCs and antagonizes the expression of MN-related genes. The mechanism underlying the differential expression of Olig2 in MNs and oligodendrocytes remains unknown. Here, we report that activation of WNT/ $\beta$-catenin signaling in pMN lineage cells abolished Olig2 expression coupled with a dramatic increase of Ngn2 expression. Luciferase reporter assay showed that Ngn2 inhibited Olig2 promoter activity. Overexpression of Ngn2-EnR transcription repressor blocked the expression of Olig2 in ovo. Our results suggest that down-regulation of WNT-Ngn2 signaling contributes to oligodendrogenesis from the pMN domain and the persistent Olig2 expression in OPCs.
\end{abstract}

Keywords: WNT, $\beta$-catenin, Oligodendrocyte, Ngn2, Olig2

Olig2 is the key transcription factor that not only maintains the neural progenitor cells (NPCs) of pMN domain, but also regulates the sequential specification of NPCs into motor neurons (MNs) and OPCs [1-5]. Since persistent expression of Olig2 is inhibitory to post-mitotic MN genes [6], the expression of Olig2 rapidly declines in newly generated MNs, but remains high in later-born cells of oligodendrocyte lineage [2-6]. The mechanism of down-regulation of Olig2 expression in MNs remains elusive. WNT signaling is known to regulate the balance between the proliferation and differentiation of NPCs during neurogenesis [7]. It is interesting that endogenous $\mathrm{WNT} / \beta$-catenin signaling is activated in newly generated MNs [8]. Activation of $\mathrm{WNT} / \beta$-catenin signaling has been reported to inhibit the specification of OPCs and

\footnotetext{
*Correspondence: m0qiu001@yahoo.com; zhongmindai@hznu.edu.cn Institute of Life Sciences, Key Laboratory of Organ Development and Regeneration of Zhejiang Province, College of Life Sciences, Hangzhou Normal University, Hangzhou 310029, People's Republic of China
}

astrocytes from NPCs during early stages of gliogenesis [9-11]. However, the mechanism underlying the inhibition of OPC specification from $\mathrm{pMN}$ NPCs by WNT/ $\mathrm{W}$ catenin signaling remains to be determined.

Here, we utilized the $\mathrm{Olig} 1^{\mathrm{Cre} /+} ; \mathrm{Ctnnb1}^{\mathrm{DEx} 3 /+}$ transgenic mice to activate WNT signaling in the pMN domain. At embryonic day 12.5 (E12.5) when oligodendrogenesis commences, expression of Olig1 and Olig2 remains high in the pMN neural progenitor cells from which Pdgfra+OPCs arise (Fig. 1a). Strikingly, in $\mathrm{Olig1}^{\mathrm{Cre} /+} ; \mathrm{Ctnnb1}^{\mathrm{Ex} \times 3 /+}$ transgenic mice, activation of WNT signaling totally abolished the expression of Olig1, Olig2 and Pdgfra (Fig. 1a), indicating a complete inhibition of oligodendrogenesis. By contrast, the number of ISL1-positive MNs was only decreased slightly in Olig $1^{\mathrm{Cre} /+} ;$ Ctnnb $^{\Delta \mathrm{Ex} 3 /+}$ mice (Additional file 1: Fig. S1), consistent with the previous finding that Olig1 is intermittently expressed in pMN NPCs and only weakly expressed during neurogenesis stage [12]. Although Olig $1^{\text {Cre }}$ was also transcribed in P3 domain at early stages original author(s) and the source, provide a link to the Creative Commons licence, and indicate if changes were made. The images or other third party material in this article are included in the article's Creative Commons licence, unless indicated otherwise in a credit line to the material. If material is not included in the article's Creative Commons licence and your intended use is not permitted by statutory regulation or exceeds the permitted use, you will need to obtain permission directly from the copyright holder. To view a copy of this licence, visit http://creativecommons.org/licenses/by/4.0/. The Creative Commons Public Domain Dedication waiver (http://creativeco mmons.org/publicdomain/zero/1.0/) applies to the data made available in this article, unless otherwise stated in a credit line to the data. 


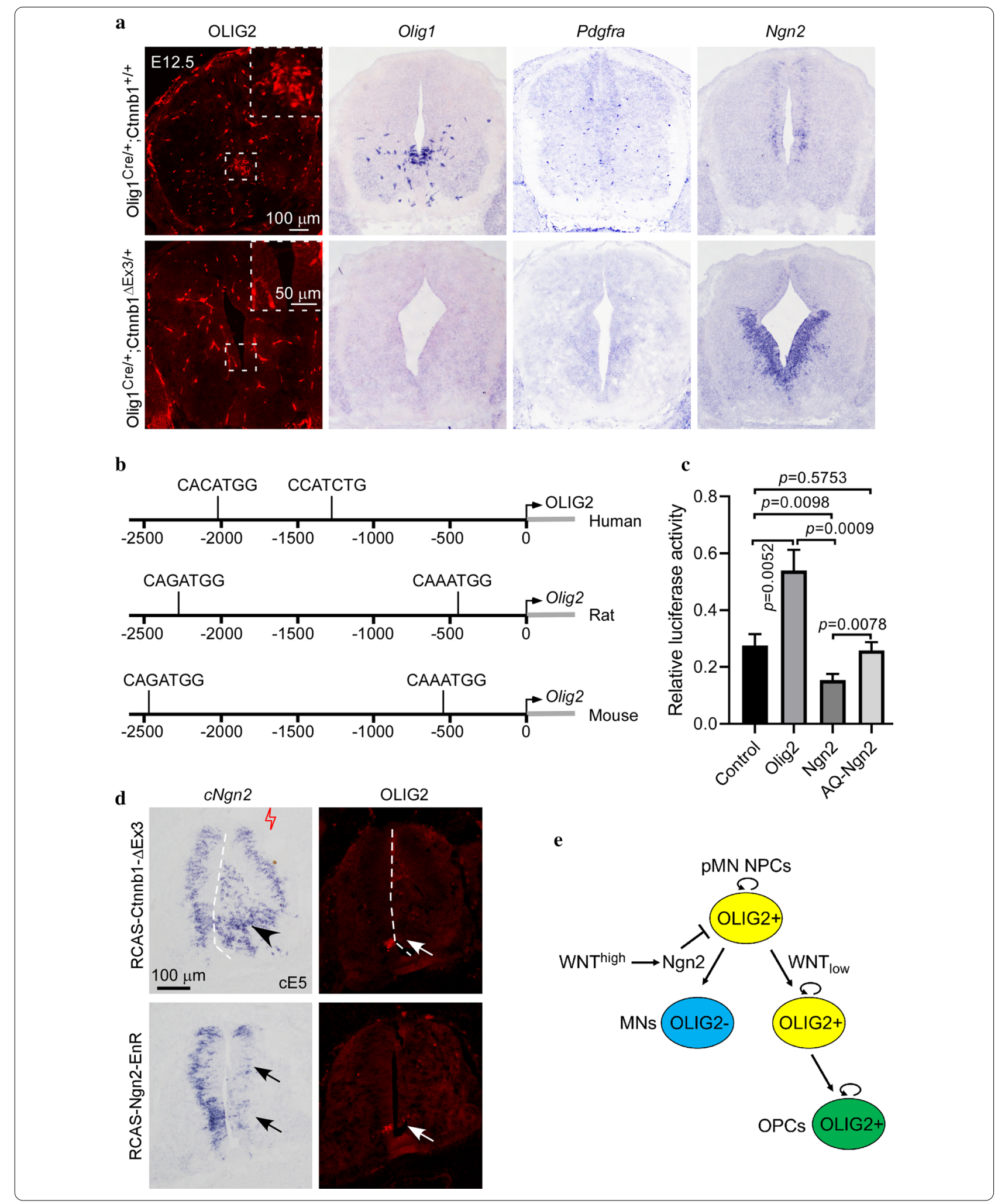




\begin{abstract}
(See figure on previous page.)
Fig. 1 WNT signaling inhibit Olig2 expression through upregulation of Ngn2 expression. a Transverse sections of spinal cord at E12.5 from control and WNT signaling activated (Olig $1^{\mathrm{Cre} /{ }^{+}} ; \mathrm{Ctnnb} 1^{\Delta \mathrm{EX} 3 /+}$ ) mice were subjected to IF with anti-OLIG 2 antibody or ISH with Olig 1, Pdgfra and

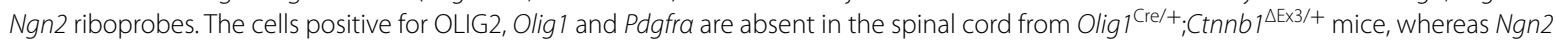
is upregulated. Inset highlights the expression of OLIG2 in pMN domain, note that vascular development was abnormal in the spinal cord of

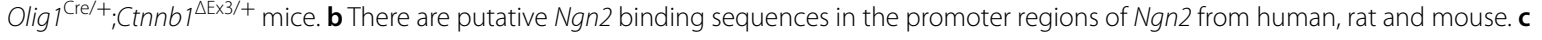
Luciferase report assay revealed that Ngn2 but not its DNA binding deficient mutant AQ-Ngn2 inhibit the promoter activity of mouse Olig2. ${ }^{*} p<0.05$, t-test. $\mathbf{d}$ Over-expression of Ngn2-EnR mimics the phenotype caused by over-expression of Ctnnb1- $\triangle$ Ex3. Both expression of Ctnnb1- $\Delta$ Ex3 and Ngn2-EnR suppressed the expression of OLIG2 in ovo. Arrowhead indicates induced expression of chick Ngn2 (cNgn2). Arrows represent reduced expression of endogenous genes. e OLIG2 maintains proliferation of pMN domain neural progenitor cells. High level of WNT signaling upregulates Ngn2 expression, NGN2 in turn coordinate with OLIG2 to promote motor neurons specification and suppress Olig2 expression in newly generated motor neurons. OPCs were specified OLIG2+ cells when WNT signaling is declined at the gliogenesis stage
\end{abstract}

$[13,14]$, expression of P3 domain marker NKX2-2 was not suppressed in $\mathrm{Olig} 1^{\mathrm{Cre} /+} ; \mathrm{Ctnn}_{\mathrm{H}}{ }^{\mathrm{\Delta Ex} 3 /+}$ mice (Additional file 1: Fig. S1). However, the number of Ngn2positive cells was dramatically increased within the ventral ventricular region in $\mathrm{Olig} 1^{\mathrm{Cre} /+} ; \mathrm{Ctnn}_{n} 1^{\Delta \mathrm{Ex} 3 /+}$ mice (Fig. 1a), demonstrating that WNT activation promotes Ngn2 expression. In support of this notion, overexpression of $C t n n b 1^{\Delta \mathrm{Ex} 3}$ in embryonic chicken spinal cord also caused an increase of Ngn2 expression, coupled with a reduced expression of Olig2 (Fig. 1d). At E18.5, although a few dorsally-derived [15-17] OPCs were generated

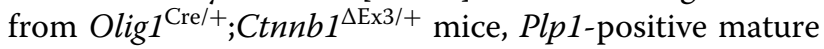
oligodendrocytes were still undetectable (Additional file 1: Fig. S2) since dorsal OPCs differentiate only after birth [14]. Together, these results strongly suggest that $N g n 2$ is the candidate gene that mediates the suppression of oligodendrogenesis from pMN NPCs by WNT signaling.

In line with this concept, two NGN2 recognition sequences are identified in the upstream promoter of the Olig2 gene in human, rat and mouse (Fig. 1b). Luciferase reporter assay revealed that Ngn2 but not its DNA binding defective mutant AQ-Ngn2 can inhibit the promoter activity of mouse Olig2 (Fig. 1c), demonstrating that $\mathrm{Ngn} 2$ can bind to the promoter of Olig2 and repress its expression. To confirm that Ngn2 mediates WNT inhibition of oligodendrogenesis, we overexpressed Ngn2 in embryonic chicken spinal cord by in ovo electroporation and found a significant decrease of Olig2 and Pdgfra expression in the electroporated side at CE7 (Additional file 1: Fig. S3). Since Ngn2 can function either as a transcriptional activator or a repressor, we next investigated whether the inhibition of Olig2 expression is mediated by the transcriptional repressor activity of $N g n 2$. RCAS-Ngn2-EnR (DNA binding domain of NGN2 fused with EnR transcription repressor) was employed as a repressor-only NGN2 chimeric protein. It was found that overexpression of this chimeric repressor caused a significant reduction of Olig2 expression (Fig. 1d), mimicking the effect of full-length Ngn2 protein. This finding demonstrated that Ngn2 inhibits Olig2 expression by its transcriptional repressor activity.

In conclusion, our results suggest that WNT signaling up-regulates the expression of $N g n 2$, and $N g n 2$ in turn inhibits Olig2 expression and oligodendrogenesis during MN specification (Fig. 1e).

\section{Supplementary information}

Supplementary information accompanies this paper at https://doi. org/10.1186/s13041-020-00696-0.

Additional file 1: Supplementary materials and results.

\section{Acknowledgements}

Not applicable.

\section{Authors' contributions}

ZMD conceived the project. MJ, DY, BX, HH, WL and ZMD performed the experiments. MJ, DY, BX, HH, MQ, WL and ZMD analyzed the data. MQ and ZMD supervised the project. MJ, MQ and ZMD wrote the paper with input from the other authors. All authors read and approved the final manuscript.

\section{Funding}

This work was supported by the National Natural Science Foundation of China (Grant No. 31871480, 81771028, 31771621); the Natural Science Foundation of Zhejiang Province (Grant No. LY18C090009, LQ15C070001, LQ18C090005).

\section{Availability of data and materials}

All date generated during this study are included in this article.

\section{Ethics approval and consent to participate}

The use of animals was approved by the Committee on Laboratory Animals, Hangzhou Normal University.

\section{Consent for publication}

Not applicable.

\section{Competing interests}

The authors declare that they have no conflict of interest.

Received: 30 July 2020 Accepted: 6 November 2020

Published online: 13 November 2020

\section{References}

1. Li H, de Faria JP, Andrew P, Nitarska J, Richardson WD. Phosphorylation regulates OLIG2 cofactor choice and the motor neuron-oligodendrocyte fate switch. Neuron. 2011;69(5):918-29. 
2. Lu QR, Sun T, Zhu Z, Ma N, Garcia M, Stiles CD, et al. Common developmental requirement for Olig function indicates a motor neuron/oligodendrocyte connection. Cell. 2002;109(1):75-86.

3. Mizuguchi R, Sugimori M, Takebayashi H, Kosako H, Nagao M, Yoshida S, et al. Combinatorial roles of olig2 and neurogenin2 in the coordinated induction of pan-neuronal and subtype-specific properties of motoneurons. Neuron. 2001;31(5):757-71.

4. Novitch BG, Chen Al, Jessell TM. Coordinate regulation of motor neuron subtype identity and pan-neuronal properties by the bHLH repressor Olig2. Neuron. 2001;31(5):773-89.

5. Zhou Q, Anderson DJ. The bHLH transcription factors OLIG2 and OLIG1 couple neuronal and glial subtype specification. Cell. 2002;109(1):61-73.

6. Lee SK, Lee B, Ruiz EC, Pfaff SL. Olig2 and Ngn2 function in opposition to modulate gene expression in motor neuron progenitor cells. Genes Dev. 2005;19(2):282-94.

7. Zechner D, Fujita Y, Hulsken J, Muller T, Walther I, Taketo MM, et al. betaCatenin signals regulate cell growth and the balance between progenitor cell expansion and differentiation in the nervous system. Dev Biol. 2003;258(2):406-18.

8. Demireva EY, Shapiro LS, Jessell TM, Zampieri N. Motor neuron position and topographic order imposed by beta- and gamma-catenin activities. Cell. 2011;147(3):641-52.

9. Dai ZM, Sun S, Wang C, Huang H, Hu X, Zhang Z, et al. Stage-specific regulation of oligodendrocyte development by $\mathrm{Wnt} /$ beta-catenin signaling. J Neurosci. 2014;34(25):8467-73.

10. Sun S, Guo W, Zhang Z, Qiu M, Dai ZM. Dose-dependent regulation of oligodendrocyte specification by beta-catenin signaling. Neurosci Bull. 2015;31(2):271-3.
11. Sun S, Zhu XJ, Huang H, Guo W, Tang T, Xie B, et al. WNT signaling represses astrogliogenesis via Ngn2-dependent direct suppression of astrocyte gene expression. Glia. 2019;67(7):1333-43.

12. Zhou Q, Wang S, Anderson DJ. Identification of a novel family of oligodendrocyte lineage-specific basic helix-loop-helix transcription factors. Neuron. 2000;25(2):331-43.

13. Wu S, Wu Y, Capecchi MR. Motoneurons and oligodendrocytes are sequentially generated from neural stem cells but do not appear to share common lineage-restricted progenitors in vivo. Development. 2006;133(4):581-90.

14. Zheng K, Li H, Zhu Y, Zhu Q, Qiu M. MicroRNAs are essential for the developmental switch from neurogenesis to gliogenesis in the developing spinal cord. J Neurosci. 2010;30(24):8245-50.

15. Cai J, Qi Y, Hu X, Tan M, Liu Z, Zhang J, et al. Generation of oligodendrocyte precursor cells from mouse dorsal spinal cord independent of Nkx6 regulation and Shh signaling. Neuron. 2005;45(1):41-53.

16. Vallstedt A, Klos JM, Ericson J. Multiple dorsoventral origins of oligodendrocyte generation in the spinal cord and hindbrain. Neuron. 2005;45(1):55-67.

17. Fogarty M, Richardson WD, Kessaris N. A subset of oligodendrocytes generated from radial glia in the dorsal spinal cord. Development. 2005;132(8):1951-9.

\section{Publisher's Note}

Springer Nature remains neutral with regard to jurisdictional claims in published maps and institutional affiliations.
Ready to submit your research? Choose BMC and benefit from:

- fast, convenient online submission

- thorough peer review by experienced researchers in your field

- rapid publication on acceptance

- support for research data, including large and complex data types

- gold Open Access which fosters wider collaboration and increased citations

- maximum visibility for your research: over 100M website views per year

At BMC, research is always in progress.

Learn more biomedcentral.com/submissions 